\title{
Tillage-induced short-term soil organic matter turnover and respiration
}

\author{
Sebastian Rainer Fiedler ${ }^{1}$, Peter Leinweber ${ }^{1}$, Gerald Jurasinski ${ }^{1}$, Kai-Uwe Eckhardt ${ }^{1}$, and \\ Stephan Glatzel ${ }^{1, \mathrm{a}}$ \\ ${ }^{1}$ University of Rostock, Faculty of Agricultural and Environmental Sciences, Rostock, Germany \\ ${ }^{a}$ now at: University of Vienna, Department of Geography and Regional Research, Vienna, Austria \\ Correspondence to: Sebastian Rainer Fiedler (sebastian.fiedler@uni-rostock.de)
}

Received: 11 December 2015 - Published in SOIL Discuss.: 19 January 2016

Revised: 6 September 2016 - Accepted: 7 September 2016 - Published: 15 September 2016

\begin{abstract}
Tillage induces decomposition and mineralisation of soil organic matter (SOM) by the disruption of macroaggregates and may increase soil $\mathrm{CO}_{2}$ efflux by respiration, but these processes are not well understood at the molecular level. We sampled three treatments (mineral fertiliser: MF; biogas digestate: BD; unfertilised control: CL) of a Stagnic Luvisol a few hours before and directly after tillage as well as 4 days later from a harvested maize field in northern Germany and investigated these samples by means of pyrolysis-field ionisation mass spectrometry (Py-FIMS) and hot-water extraction. Before tillage, the Py-FIMS mass spectra revealed differences in relative ion intensities of MF and CL compared to BD most likely attributable to the cattle manure used for the biogas feedstock and to relative enrichments during anaerobic fermentation. After tillage, the $\mathrm{CO}_{2}$ effluxes were increased in all treatments, but this increase was less pronounced in $\mathrm{BD}$. We explain this by restricted availability of readily biodegradable carbon compounds and possibly an inhibitory effect of sterols from digestates. Significant changes in SOM composition were observed following tillage. In particular, lignin decomposition and increased proportions of $\mathrm{N}$-containing compounds were detected in BD. In MF, lipid proportions increased at the expense of ammonia, ammonium, carbohydrates and peptides, indicating enhanced microbial activity. SOM composition in CL was unaffected by tillage. Our analyses provide strong evidence for significant short-term SOM changes due to tillage in fertilised soils.
\end{abstract}

\section{Introduction}

The influence of tillage on soil organic matter (SOM) is generally well understood. Tillage stimulates decomposition of SOM resulting in increased $\mathrm{CO}_{2}$ efflux (Dao, 1998), mostly by aeration and by the disruption of macro-aggregates, leading to release of protected SOM (Grandy and Robertson, 2007). In the long term, tillage promotes a shift of chemical structure and age towards more recent SOM (Grandy and Neff, 2008) due to both the mineralisation of older SOM and the decomposition of recent plant residues (Balesdent et al., 1990). In addition, tilled soils contain lower amounts of readily biodegradable (hereinafter referred to as "labile") organic matter (Balota et al., 2003) and have an increased potential for mineralisation and nitrification (Doran, 1980), which implies a lower potential to immobilise mineral N (Follett and
Schimel, 1989; Schulten and Hempfling, 1992). However, the immediate, short-term effects of tillage events on SOM are almost unknown.

Research on short-term effects of tillage on SOM has focused largely on $\mathrm{CO}_{2}$ efflux: several studies have recorded the dynamics of $\mathrm{CO}_{2}$ efflux immediately after tillage (see Table 5 in Fiedler et al., 2015) and some basic models have been developed that describe correlations between $\mathrm{CO}_{2}$ efflux and the turnover of soil organic carbon (SOC) after tillage by first-order kinetics (La Scala et al., 2008). Admittedly, these correlations do not causally explain which organic components are mineralised. Furthermore, $\mathrm{SOM}-\mathrm{CO}_{2}$ efflux relationships are influenced by the type of soil amendment (Fiedler et al., 2015). 
Biogas digestate is a relatively new type of soil amendment, and its long-term stability in soil is still under debate, as recently reviewed by Möller (2015). Consequently, it is not clear how long-term application of biogas digestates would alter the composition of SOM, and tillage effects on short-term SOM turnover in biogas digestate-amended soils are almost unstudied. Even short-term changes in SOM may have strong effects on nutrient availability and plant productivity. A better understanding of the immediate impacts of tillage on SOM and its turnover may help to avoid adverse effects for plant growth (Franzluebbers et al., 1994).

In general, detecting changes in the molecular-chemical composition of SOM on timescales as short as days requires extremely sensitive methods. Pyrolysis-field ionisation mass spectrometry (Py-FIMS) is a very sensitive method and has been applied successfully to investigate differences in the chemical composition of SOM under different fertiliser treatments like mineral NPK fertiliser or farmyard manure (Jandl et al., 2004; Leinweber et al., 2008; Schmidt et al., 2000). Even very small alterations in the composition and stability of dissolved organic matter - a very reactive part of SOM during storage in the refrigerator (Schulten et al., 2008) or diurnal cycles of $\mathrm{CO}_{2}$ assimilation and respiration (Kuzyakov et al., 2003; Melnitchouck et al., 2005) have been detected and resolved by multivariate statistics of mass-spectrometric fingerprints. Furthermore, Py-FIMS of bulk SOM has revealed alterations in laboratory incubation experiments and allowed for these to be linked to respiration and enzyme activities (Leinweber et al., 2008). However, it is unclear whether the method is sensitive enough to detect tillageinduced SOM alterations under various fertilisation regimes and analyse its influence on $\mathrm{CO}_{2}$ efflux at the field scale, where spatial heterogeneity may interfere with the temporal dynamics much more than in the above-cited laboratory studies.

Hot-water extraction is a relatively simple method to release labile SOM and to estimate how much of soil C and N can be easily utilised by microorganisms (Leinweber et al., 1995). These labile pools have been suggested to be an important indicator of short-term changes in SOM quality due to soil management (Haynes, 2005). Furthermore, a significant proportion of hot-water-extracted organic matter originates from microbial biomass. Thus, this approach is a potential indicator for changes in microbial biomass or activity (Sparling et al., 1998), which may reflect sources of $\mathrm{CO}_{2}$ efflux following tillage.

Here, we investigate (1) short-term effects of tillage on SOM composition and (2) potential relationships between decomposable SOM fractions and measured $\mathrm{CO}_{2}$ efflux under the impact of different soil amendments by combining Py-FIMS with $\mathrm{CO}_{2}$ efflux measurements.

\section{Materials and methods}

\subsection{Study site}

The study site is located in northeastern Germany in the ground moraine of the Weichselian glacial period at $53^{\circ} 48^{\prime} 35^{\prime \prime} \mathrm{N}, 12^{\circ} 4^{\prime} 20^{\prime \prime} \mathrm{E}$ (elevation $10 \mathrm{~m}$ ) within a gently rolling relief. The soil is a Stagnic Luvisol (IUSS Working Group WRB, 2006) with sandy loam texture (sand: 63\%; silt: $26 \%$; clay: $11 \%$ ) overlying bedrock of till. The topsoil $(0-30 \mathrm{~cm})$ has an organic carbon content of $8.5 \pm 0.2 \mathrm{mg} \mathrm{g}^{-1}$ (mean \pm standard deviation, $n=9)$, $\mathrm{pH}$ of $7.4 \pm 0.9(n=3)$ and bulk density of $1.51 \pm 0.08 \mathrm{~g} \mathrm{~cm}^{-3}(n=3)$, measured according to Fiedler et al. (2015). The climate is characterised by maritime influence, with annual averages of $8.8^{\circ} \mathrm{C}$ temperature and $557 \mathrm{~mm}$ total precipitation for the 30-year period from 1985 to 2014 (Federal State Research Institute for Agriculture and Fisheries Mecklenburg-Western Pomerania (LFA), Germany, personal communication, 2015). The experiment was conducted on a field which has been cultivated with maize (Zea Mays L. 'Atletico') as feedstock for a biogas plant. Before our study period, during other trials, winter wheat (Triticum aestivum L.) and subsequently maize were grown on the field.

We compared three fertiliser treatments: CL - without fertiliser (control); MF - with mineral fertiliser; and BD - with biogas digestate. The size of the three experimental plots was $6 \mathrm{~m} \times 30 \mathrm{~m}$ each. In both fertilised treatments, equal overall amounts of plant-available $\mathrm{N}$ were applied $\left(160 \mathrm{~kg} \mathrm{ha}^{-1}\right)$ on 26 April 2012. The mineral fertiliser calcium ammonium nitrate was top-dressed, whereas the biogas digestate was injected into the soil down to $10 \mathrm{~cm}$ depth with a track width of $25 \mathrm{~cm}$. Following recommendations of the LFA (personal communication, 2012), a mineral fertiliser equivalent of $70 \%$ of total $\mathrm{N}$ in the biogas digestates $\left(229 \mathrm{~kg} \mathrm{Nha}^{-1}\right)$ was assumed. The digestate for this single application originated from anaerobic fermentation of $91 \%$ cattle slurry, $7 \%$ rye groats and $2 \%$ maize silage; it had a pH of 8.1 and $3.8 \%$ $\mathrm{C}, 0.5 \%$ total $\mathrm{N}$ and $0.3 \% \mathrm{NH}_{4}-\mathrm{N}$ in undried material. During the cropping season 2012, maize was grown according to conventional agricultural practice.

Sixteen days after harvest of the maize (8 October 2012), the field site was first tilled with a Väderstad Carrier 300 disc harrow down to $10 \mathrm{~cm}$ depth (24 October, about 09:15LT) and then with a Överum CX 490 reversible mouldboard plough down to $30 \mathrm{~cm}$ depth on the subsequent day (25 October, about 11:30 LT).

\section{2 $\mathrm{CO}_{2}$ concentration measurement and estimation of $\mathrm{CO}_{2}$ efflux}

For measuring $\mathrm{CO}_{2}$ exchange, we permanently installed three replicate bases in each treatment after fertilisation in spring, which were removed for tillage and inserted back afterwards. The adjacent bases were placed $1 \mathrm{~m}$ apart. The 
bases had dimensions of $79 \mathrm{~cm} \times 79 \mathrm{~cm}$ and a total height of $15 \mathrm{~cm}$ and were installed into the soil down to $12 \mathrm{~cm}$ depth. The $\mathrm{CO}_{2}$ concentration measurements where performed with two LI-COR (Lincoln, NE, USA) LI-820 infrared gas analysers, each connected to a non-steady-state closed chamber that was placed on the bases during measurements. The chambers had an area of $0.6241 \mathrm{~m}^{2}$ and a height of $0.55 \mathrm{~m}$, resulting in a chamber volume of $0.34 \mathrm{~m}^{3}$, and were equipped with small fans $(80 \mathrm{~mm} \times 80 \mathrm{~mm} \times 25 \mathrm{~mm}$, $3000 \mathrm{rpm}, 68 \mathrm{~m}^{3} \mathrm{~h}^{-1}$ ) in order to mix and homogenise the air inside the chambers. Due to the successive measurement of the replicate bases in each treatment, we obtained pseudoreplications.

During chamber placement, we recorded $\mathrm{CO}_{2}$ concentrations in the chamber headspace with $1.3 \mathrm{~s}$ intervals for 3 to $5 \mathrm{~min}$, resulting in approximately 140 to 230 data points per measurement. Fluxes were estimated with the function "fluxx" of the package "flux" version 0.3-0 (Jurasinski et al., 2014) for the R statistical software version 2.15.2 (R Core Team, 2013). In short, the algorithm identifies the most linear part of the $\mathrm{CO}_{2}$ concentration development during chamber placement time and fits a linear regression model (Eq. 1):

$f=\frac{M p V}{R T A} \frac{\mathrm{d} c}{\mathrm{~d} t} 10^{6}$,

with $f$ the $\mathrm{CO}_{2}$ flux $\left(\mathrm{g} \mathrm{m}^{-2} \mathrm{~h}^{-1}\right), M$ the molar mass of $\mathrm{CO}_{2}$ $\left(\mathrm{g} \mathrm{mol}^{-1}\right), p$ the air pressure $(\mathrm{Pa}), V$ the chamber volume $\left(\mathrm{m}^{3}\right), R$ the gas constant $\left(\mathrm{J} \mathrm{mol}^{-1} \mathrm{~K}^{-1}\right), T$ the temperature inside the chamber $(\mathrm{K}), A$ the area covered by the chamber $\left(\mathrm{m}^{2}\right)$, and $\mathrm{d} c / \mathrm{d} t$ the $\mathrm{CO}_{2}$ concentration change over time $\left(\mathrm{ppm} \mathrm{h}^{-1}\right)$. The minimum proportion of data points to be kept for regression analyses was $70 \%$ of a concentration measurement. This allowed for discarding of data noise at the beginning and the end resulting from chamber deployment and removal (for details, see the help file for the function "fluxx" of the package "flux"). Thus, each $\mathrm{CO}_{2}$ flux was estimated from at least 98 concentration measurements. Only linear fluxes with a concentration change of at least $10 \mathrm{ppm}$, a normalised root-mean-square error (NRMSE) $\leq 0.15$ and a coefficient of determination $\left(R^{2}\right)$ of at least 0.85 were included in further analyses. We assumed linearity of concentration change and did not test for non-linearity since $95.1 \%$ of the obtained linear regressions had $R^{2} \geq 0.95$.

To obtain reference data from before tillage operations, the undisturbed site was measured hourly between 07:00 and 13:00 LT on 19 October 2012 (i.e. between harvest and tillage). The intervals between measurements before, during and after tillage operations were varied to effectively capture the development of $\mathrm{CO}_{2}$. The measurements immediately after the tillage operations were conducted within $1 \mathrm{~min}$ by inserting the collars and putting on the airtight chambers. The timeline ( 24 until 29 October) of tillage events, soil samplings and the respective $\mathrm{CO}_{2}$ measurements, together with soil temperature, is shown in Fig. 1. After this period,

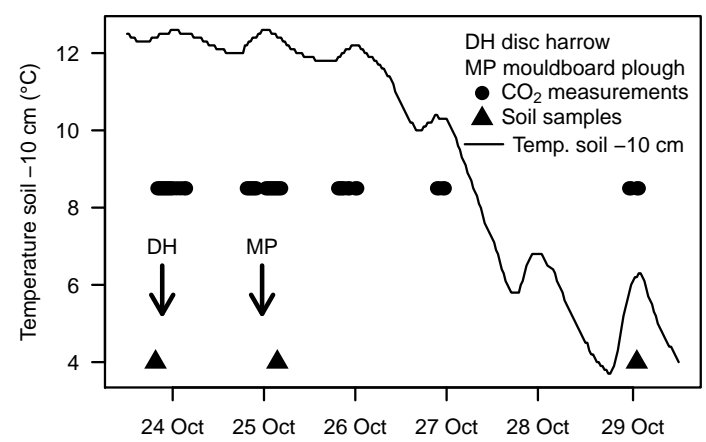

Figure 1. Timeline of the soil sampling and the $\mathrm{CO}_{2}$ measurements in relation to the tillage events. Additionally, soil temperature at $10 \mathrm{~cm}$ depth, which was recorded every $30 \mathrm{~min}$ with an automated meteorological station (DALOS 535, F \& C, Gülzow, Germany), is plotted.

$\mathrm{CO}_{2}$ measurements were performed hourly before noon on 1 , 5 and 9 November.

\subsection{Soil sampling and analyses}

Three replicates of bulk soil samples were taken between 0 and $10 \mathrm{~cm}$ depth (depending on unevenness of soil surface due to tillage) directly with three soil sample rings $\left(h=6.1 \mathrm{~cm}, V=250 \mathrm{~cm}^{3}\right)$ in a triangular arrangement around the three bases for gas sampling (see Sect. 2.2) in each treatment at three times: (1) right before the first tillage operation, (2) in the afternoon after the second tillage operation and (3) 4 days after the second tillage operation. The resulting 27 soil samples were fixed immediately with liquid nitrogen and split thereafter into subsamples for freeze drying and for oven drying at $60^{\circ} \mathrm{C}$.

For Py-FIMS, the freeze-dried samples were finally ground and homogenised using a planetary ball mill. Then, about $2 \mathrm{~g}$ of each sample was transferred into a Petri dish with a spatula and three crucibles were filled by drawing them across the dishes. These subsamples of about $5 \mathrm{mg}$ were thermally degraded in the ion source (emitter: $4.7 \mathrm{kV}$; counter electrode $-5.5 \mathrm{kV}$ ) of a double-focusing Finnigan MAT 95 mass spectrometer (Finnigan, Bremen, Germany). The samples were heated in a vacuum of $10^{-4} \mathrm{~Pa}$ from 50 to $700^{\circ} \mathrm{C}$, in temperature steps of $10^{\circ} \mathrm{C}$ over a time period of $15 \mathrm{~min}$. Between magnetic scans the emitter was flash heated to avoid residues of pyrolysis products. The Py-FIMS mass spectra of each sample were gained by the integration of 65 single scans in a mass range of $15-900 \mathrm{~m} / \mathrm{z}$. Ion intensities were referred to $1 \mathrm{mg}$ of the sample. Volatile matter was calculated as mass loss in percentage of sample weight. For plotting, the three replicates of each sample were then averaged to one final survey spectrum. Moreover, thermograms were compiled for the total ion intensities. The assignment of marker signals to chemical compounds from the survey spectra were interpreted according to Leinweber et al. (2013) to obtain the 
relative abundance of ten SOM compound classes: (1) carbohydrates, (2) phenols and lignin monomers, (3) lignin dimers, (4) lipids, alkanes, alkenes, bound fatty acids and alkyl monoesters, (5) alkyl aromatics, (6) mainly heterocyclic $\mathrm{N}$ containing compounds, (7) sterols, (8) peptides, (9) suberin, and (10) free fatty acids.

Subsamples of oven-dried and sieved soil $(2 \mathrm{~mm})$ were used for determination of total and hot-water-extracted $\mathrm{C}$ and $\mathrm{N}$. For determination of total $\mathrm{C}$ and $\mathrm{N}, 1 \mathrm{~g}$ of ground soil was analysed with a vario Max CN elemental analyser (elementar Analysensysteme GmbH, Hanau, Germany) based on hightemperature combustion at up to $1200^{\circ} \mathrm{C}$ with subsequent gas analysis. For hot-water extraction, $20 \mathrm{~g}$ of soil was boiled in $40 \mathrm{~mL}$ of deionised water for $60 \mathrm{~min}$ (Leinweber et al., 1995). After filtration with pleated filters $\left(240 \mathrm{~mm}, 80 \mathrm{~g} \mathrm{~m}^{-2}\right)$ by Munktell (Falun, Sweden), extracts were analysed with a DIMATOC 2000 (DIMATEC Analysentechnik GmbH, Essen, Germany) for determination of hot-water-extractable organic $\mathrm{C}$ (HWC) as well as organic and inorganic bound N, often referred to as "total nitrogen bound" (HWN). These measurements of organic $\mathrm{C}$ and total nitrogen bound are based on the principle of thermal-catalytic oxidation with subsequent NDIR detection and the principle of chemiluminescence, respectively. For each sample, two replicates were analysed and results were averaged for further calculations.

\subsection{Statistical analyses}

All statistical analyses were run using R 2.15.2 (R Core Team, 2013). The cumulated $\mathrm{CO}_{2}$ effluxes were estimated by a bootstrap method with the function "auc.mc" of the R package "flux" version 0.3-0 (Jurasinski et al., 2014). In detail, the $\mathrm{CO}_{2}$ fluxes were cumulated in 250 iterations, while for each run 25 fluxes were omitted randomly for the period after tillage. For the reference period before tillage, in each iteration run, four fluxes were omitted randomly. The numbers of randomly omitted fluxes per run correspond to roughly one-fifth of the recorded fluxes per treatment in the respective periods. The resulting data were used to calculate means and standard deviations. Tukey's HSD test was applied to test for differences in means of $\mathrm{CO}_{2}$ fluxes as well as HWC and HWN between sampling periods and treatments against a significance level of $\alpha<0.05$. Py-FIMS signals of the compound classes were tested for differences in means by Tukey's HSD test against a significance level of $\alpha<0.1$ since the number of replicates was limited and the variances were rather high.

A principal component analysis (PCA) was applied to the mass signals with significant differences between the samples according to the univariate Wilks' $\lambda(p<0.001)$ with function "rda" of R package "vegan" version 2.3-0 (Oksanen et al., 2015).

Partial least-squares regression (PLSR) was used for discrimination (Barker and Rayens, 2003) to explore linkages between shifts in the $\mathrm{m} / \mathrm{z}$ data by tillage and shifts in $\mathrm{CO}_{2}$ ef- flux. PLSR models were built using function "autopls" of the R package "autopls" version 1.3 (Schmidtlein et al., 2015) with stepwise backward selection combined with a 10 -fold cross-validation to substantially reduce the number of variables, i.e. to extract the variables with the highest explanatory power. The PLSR procedure was repeated 10000 times to yield coherent results since the obtained PLSR models differed widely both in the number and in the choice of variables and thus in their predictive performance. Based on the performance index suggested by Bauwe et al. (2015), the 500 "best" models were obtained and, finally, the mass signals which were utilised more than 50 times in the latter models were extracted.

\section{Results}

\subsection{Soil organic carbon, nitrogen, hot-water-extractable carbon and hot-water-extractable nitrogen}

One of the replicates in MF exhibited exceptionally low HWC and HWN values. According to Dixon's $Q$ test, these values were outliers (one-third and one-half, respectively, as high as for the other replicates in MF) and thus excluded from further analysis. Before tillage, the soil of all treatments had similar $\mathrm{C}$ and HWC contents, but differences appeared between MF and $\mathrm{BD}$, where the $\mathrm{N}$ and $\mathrm{HWN}$ contents were slightly higher in MF, resulting in narrower $\mathrm{C} / \mathrm{N}$ and $\mathrm{HWC} / \mathrm{HWN}$ ratios in MF (8.5 and 5.9, respectively) compared to BD (9.0 and 8.5, respectively) (Table 1). The $\mathrm{C}, \mathrm{N}$ and HWC contents of all treatments changed only slightly after tillage, but the HWN content of soil in BD increased significantly $(p<0.05)$ from $0.05 \mathrm{mg} \mathrm{g}^{-1}(5.6 \%$ of $\mathrm{N})$ to $0.07 \mathrm{mg} \mathrm{g}^{-1}(7.4 \%$ of $\mathrm{N})$, resulting in a significant $(p<0.05)$ narrowing of the HWC/HWN ratio from 8.5 to 6.0 (Table 1$)$.

\subsection{Soil $\mathrm{CO}_{2}$ efflux}

Five days before the tillage operations (19 October 2012), the mean efflux rates (all in $\mathrm{g} \mathrm{CO}_{2}-\mathrm{C} \mathrm{m}^{-2} \mathrm{~h}^{-1}$ ) were 0.133 (CL), 0.192 (MF) and 0.173 (BD), with the efflux being significantly lower from $\mathrm{CL}$ than from the amended plots MF and BD $(p<0.05)$ (Fig. 2). In the morning before the first tillage operation with a disc harrow (24 October), the effluxes had similar magnitudes and proportions to 5 days before $\left(\mathrm{CL}=0.147, \mathrm{MF}=\mathrm{BD}=0.199\right.$, all in $\left.\mathrm{g} \mathrm{CO}_{2}-\mathrm{C} \mathrm{m}^{-2} \mathrm{~h}^{-1}\right)$. After harrowing, $\mathrm{CO}_{2}$ effluxes increased to 0.849 (CL), $0.833(\mathrm{MF})$ and $0.479(\mathrm{BD})$. Over the next $5.5 \mathrm{~h}$, these values declined to 0.602 (CL), 0.460 (MF) and $0.276(\mathrm{BD})$, resulting in overall mean effluxes of 0.554 (CL), 0.481 (MF) and $0.344(\mathrm{BD})$, with the latter being now significantly lower $(p<0.05)$ than CL or MF during the measured period after harrowing. Directly before the second tillage operation with a reversible mouldboard plough in the morning of the following day (25 October), the mean effluxes were 0.299 (CL), 
Table 1. Means and standard deviations of soil organic carbon $(\mathrm{C})$, nitrogen $(\mathrm{N}), \mathrm{C} / \mathrm{N}$ ratio, hot-water-extractable carbon $(\mathrm{HWC})$ and nitrogen (HWN) and HWC / HWN ratio before (Pre), after (Post) and 4 days after tillage (Post +4$)$. Different letters $\left({ }^{\mathrm{a}}\right.$, $\left.^{\mathrm{b}}\right)$ in each column within treatments (BD, biogas digestate; MF, mineral fertiliser; $\mathrm{CL}$, control) indicate significant differences (Tukey's HSD test, $p<0.05$ ) in means.

\begin{tabular}{llcccccc}
\hline Treatment & Date & $\mathrm{C}\left(\mathrm{mg} \mathrm{g}^{-1}\right)$ & $\mathrm{N}\left(\mathrm{mg} \mathrm{g}^{-1}\right)$ & $\mathrm{C} / \mathrm{N}$ & $\mathrm{HWC}\left(\mathrm{mg} \mathrm{g}^{-1}\right)$ & $\mathrm{HWN}\left(\mathrm{mg} \mathrm{g}^{-1}\right)$ & $\mathrm{HWC} / \mathrm{HWN}$ \\
\hline \multirow{3}{*}{$\mathrm{BD}$} & Pre & $8.4 \pm 0.1$ & $0.9 \pm 0.0$ & $9.0 \pm 0.1$ & $0.44 \pm 0.02$ & $0.05 \pm 0.00^{\mathrm{a}}$ & $8.5 \pm 0.1^{\mathrm{a}}$ \\
& Post & $8.5 \pm 0.1$ & $1.0 \pm 0.0$ & $8.8 \pm 0.3$ & $0.44 \pm 0.03$ & $0.07 \pm 0.01^{\mathrm{b}}$ & $6.1 \pm 0.4^{\mathrm{b}}$ \\
& Post +4 & $8.4 \pm 0.6$ & $1.0 \pm 0.0$ & $8.7 \pm 0.0$ & $0.40 \pm 0.02$ & $0.07 \pm 0.01^{\mathrm{b}}$ & $6.0 \pm 0.4^{\mathrm{b}}$ \\
\hline \multirow{3}{*}{$\mathrm{MF}$} & Pre & $8.7 \pm 0.3$ & $1.0 \pm 0.0$ & $8.5 \pm 0.2$ & $0.44 \pm 0.05$ & $0.08 \pm 0.00$ & $5.9 \pm 0.8$ \\
& Post & $8.4 \pm 0.3$ & $1.0 \pm 0.0$ & $8.5 \pm 0.1$ & $0.42 \pm 0.04$ & $0.09 \pm 0.02$ & $4.9 \pm 0.7$ \\
& Post +4 & $8.6 \pm 0.2$ & $1.0 \pm 0.0$ & $8.5 \pm 0.1$ & $0.31 \pm 0.14$ & $0.06 \pm 0.01$ & $5.0 \pm 0.8$ \\
\multirow{3}{*}{$\mathrm{CL}$} & Pre & $8.5 \pm 0.2$ & $1.0 \pm 0.0$ & $8.8 \pm 0.2$ & $0.50 \pm 0.10$ & $0.06 \pm 0.02$ & $8.9 \pm 1.3$ \\
& Post & $8.6 \pm 0.2$ & $1.0 \pm 0.0$ & $8.8 \pm 0.0$ & $0.48 \pm 0.04$ & $0.05 \pm 0.01$ & $8.8 \pm 0.8$ \\
& Post +4 & $8.5 \pm 0.0$ & $1.0 \pm 0.0$ & $8.7 \pm 0.1$ & $0.40 \pm 0.03$ & $0.04 \pm 0.00$ & $9.6 \pm 0.3$ \\
\hline
\end{tabular}

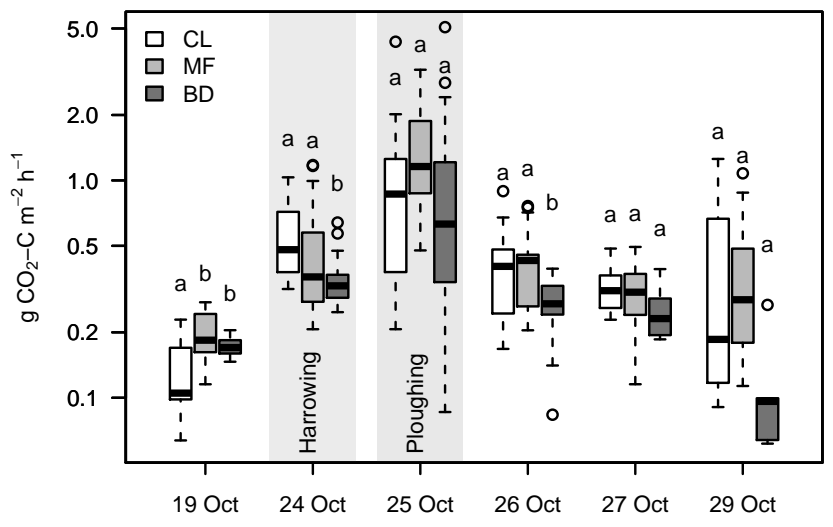

Figure 2. Soil $\mathrm{CO}_{2}$ efflux and time of tillage operations (harrowing down to $10 \mathrm{~cm}$ depth and ploughing down to $30 \mathrm{~cm}$ depth). Note that, for the days of tillage ( 24 and 25 October), only the fluxes after tillage (distinguished by light-grey backgrounds) are included in order to gain a better attribution of the tillage effect. Different letters indicate significant differences (Tukey's HSD test, $p<0.05$ ) in mean fluxes of the treatments (CL, control; MF, mineral fertiliser; $\mathrm{BD}$, biogas digestate) for each measurement day.

0.249 (MF) and 0.290 (BD) (all in $\mathrm{g} \mathrm{CO}_{2}-\mathrm{C} \mathrm{m}^{-2} \mathrm{~h}^{-1}$ ). Immediately after ploughing, they increased sharply up to $2.443(\mathrm{CL}), 2.654(\mathrm{MF})$ and $3.347(\mathrm{BD})$ and declined to $0.371(\mathrm{CL}), 0.718(\mathrm{MF})$ and $0.223(\mathrm{BD})$ after $4 \mathrm{~h}$, leading to overall mean effluxes of the measured period after ploughing of $\mathrm{CL}=1.012, \mathrm{MF}=1.392$, and $\mathrm{BD}=1.020$. Although the mean $\mathrm{CO}_{2}$ fluxes within each treatment differed significantly $(p<0.05)$ from the other measured days only after ploughing (25 October), BD on average showed significantly $(p<0.05)$ lower fluxes than CL or MF after tillage on 24 and 29 October (Fig. 3), as well as on 1 November $\left(\mathrm{CL}=0.262, \mathrm{MF}=0.242, \mathrm{BD}=0.113\right.$, all in $\mathrm{g} \mathrm{CO}_{2}$ $\left.\mathrm{C} \mathrm{m}^{-2} \mathrm{~h}^{-1}\right)$ and 5 November $(\mathrm{CL}=0.331, \mathrm{MF}=0.316$, $\mathrm{BD}=0.074$, all in $\mathrm{g} \mathrm{CO}_{2}-\mathrm{C} \mathrm{m}^{-2} \mathrm{~h}^{-1}$ ).

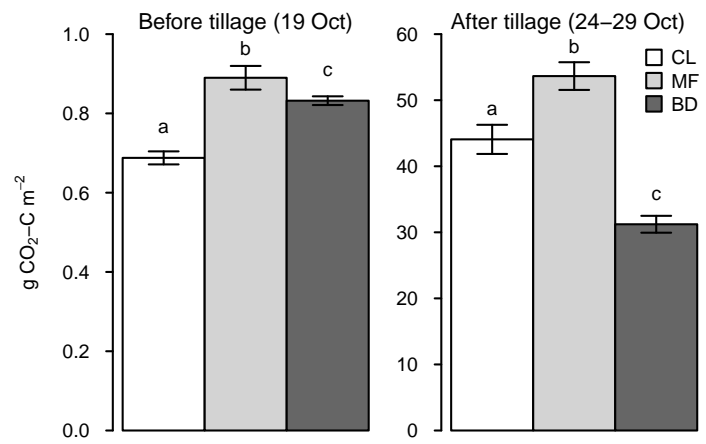

Figure 3. Cumulated soil $\mathrm{CO}_{2}$ effluxes on a day before (19 October, between 07:00 and 13:00 LT) and the period (24 October, 07:00 LT29 October, 13:00 LT) tillage. Different letters indicate significant differences (Tukey's HSD test, $p<0.05$ ) in means of the cumulated fluxes of the treatments (CL, control; MF, mineral fertiliser; $\mathrm{BD}$, biogas digestate) before and after. Error bars represent the standard deviation of interpolation by bootstrapping after 250 iteration runs.

\subsection{Pyrolysis-field ionisation mass spectrometry}

The thermograms of total ion intensity (TII) and the PyFIMS mass spectra of the soil samples of CL and MF taken before tillage were similar, whereas the ones of BD differed markedly from those two (Fig. 4): the TII thermograms of $\mathrm{CL}$ and MF had a peak at $480^{\circ} \mathrm{C}$, but BD displayed a pronounced bimodal shape with a first volatilisation maximum at about $390^{\circ} \mathrm{C}$ which was less marked in CL and MF. Furthermore, the mass spectrum of BD differed distinctly from the mass spectra of MF and CL; in particular, the abundance of marker signals for carbohydrates and peptides (e.g. $m / z 58$, $60,84,69,110,126$ and 162) was lower. Apart from this the spectra are dominated by signals for lignin monomers and dimers (e.g. $m / 2,150,208,222,244)$ as well as for homologous series of alkenes and alkadienes from $n-\mathrm{C}_{18}$ up (e.g. $m / z 252,264 / 266,278 / 280,294,308,322,336,364$, 392, 406) (Fig. 4). 

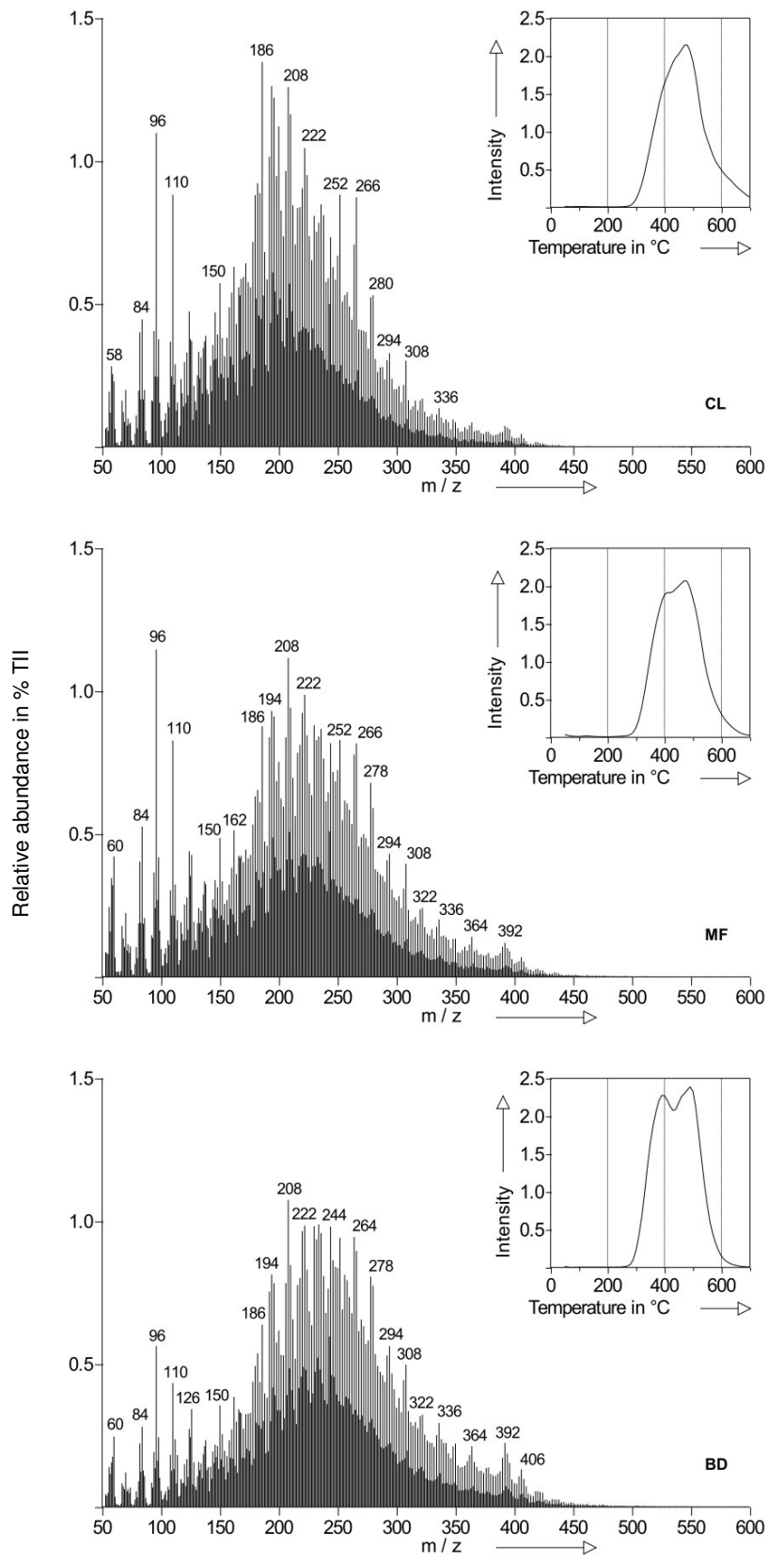

Figure 4. Thermograms of total ion intensity (TII, upper right insets) and summed pyrolysis-field ionisation mass spectra of the treatments (CL, control; MF, mineral fertiliser; $\mathrm{BD}$, biogas digestate) before tillage.

After discriminant function analysis with Wilks' $\lambda$, the resulting significant relative mass signals $(p<0.001, n=67)$ were further explored by PCA. The first two principal components accounted for 78.3 and $8.3 \%$ of total variance. All treatments are well separated from each other (Fig. 5), with CL mainly in the third quadrant, MF mainly in the first quadrant and BD spanning from the second to the fourth quadrant. According to this analysis, samples from MF and BD taken

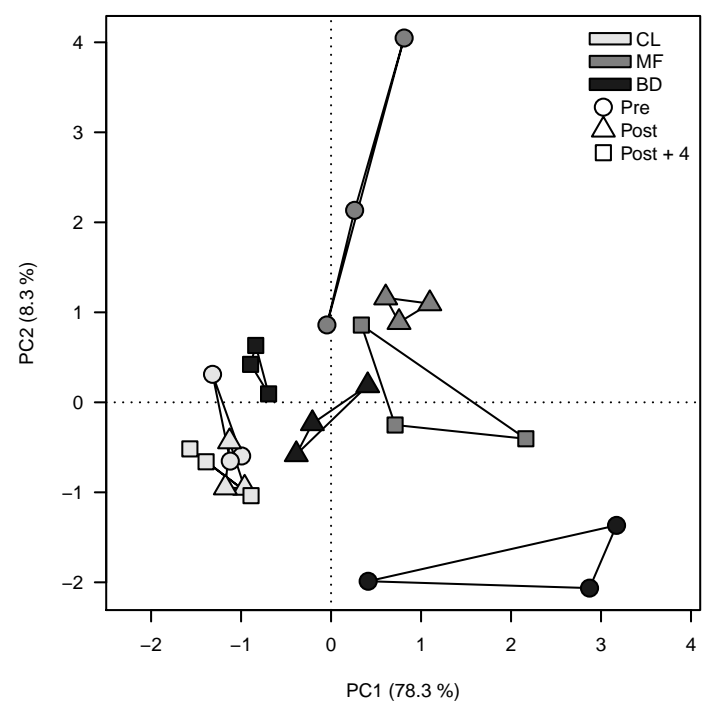

Figure 5. Principal component analysis of mass signals with significant differences according to Wilks' $\lambda$. Treatments (CL, control; MF, mineral fertiliser; BD, biogas digestate) and sampling times (pre-tillage, post-tillage and post-tillage +4 days) are depicted by different colours and symbols, respectively. Since the areas integrated by the corresponding three sampling points do not overlap for the fertilised treatments, significant distinctions and changes in relative SOM composition can be assumed before and after tillage, respectively.

before the tillage events (Pre) showed the largest differences in composition. The PCA separated the samples taken at different dates (Pre, Post and Post +4 ) in the treatments MF and $\mathrm{BD}$, but not in CL.

Basic data of the Py-FI mass spectra and the proportions of compound classes are compiled in Table 2. Approximately $46.9 \%$ of the TII in the mass spectra could be explained by $\mathrm{m} / \mathrm{z}$ signals assigned to the compound classes. Additionally, non-specific low-mass signals and isotope peaks contributed 2.6 and $14.2 \%$, respectively. Before tillage, the volatilised matter (VM) was highest in BD and increased from 5.2 to $7.1 \%$ during the days after tillage. Such an increase over time was only observed for $\mathrm{BD}$, but it was not significant $(p>0.1)$. In the other treatments, a temporal increase in VM occurred directly after the first tillage with disc harrow.

The relative (Table 2) and absolute (data not shown) ion intensities of the compound classes varied across treatments before tillage and changed differently after tillage. In the undisturbed soil, BD had the lowest proportions of carbohydrates, heterocyclic $\mathrm{N}$-containing compounds and peptides and the highest proportions of lignin dimers, lipids, sterols, suberin and free fatty acids. CL was characterised by higher proportions of phenols and lignin monomers, whereas MF ranged between $\mathrm{BD}$ and $\mathrm{CL}$ regarding the proportions of these compound classes. In $\mathrm{BD}$, the relative proportions of the samples taken after tillage displayed significant $(p<0.1)$ increases in carbohydrates, phenols and lignin monomers, 


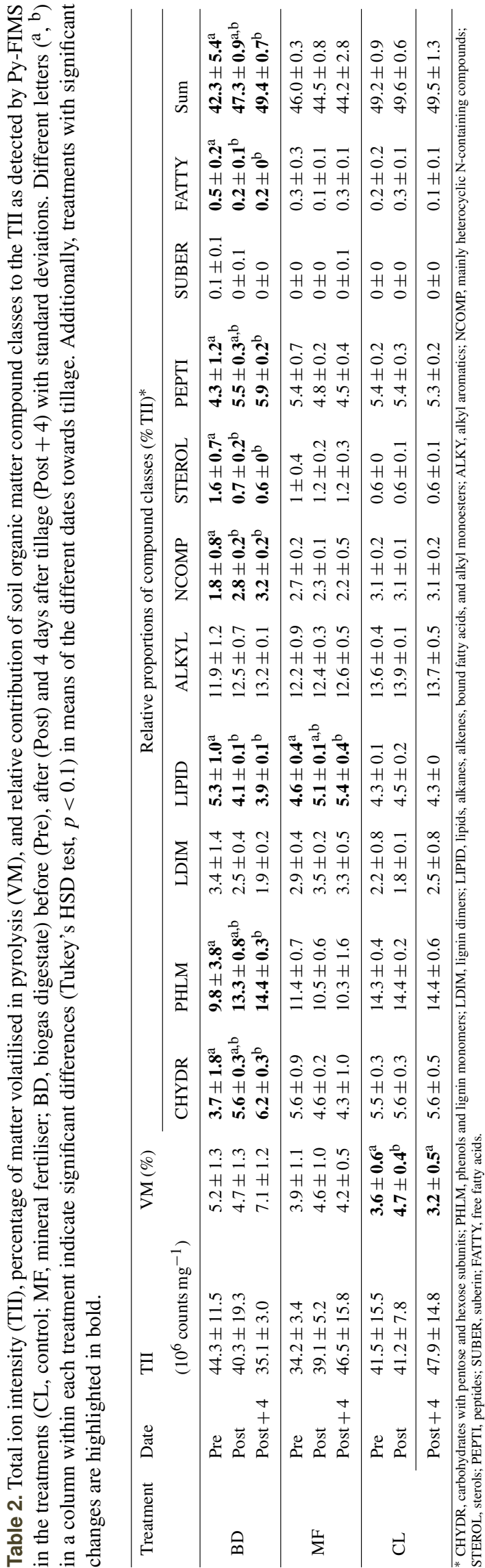

alkyl aromatics, heterocyclic $\mathrm{N}$-containing compounds and peptides, while lignin dimers, lipids, sterols and free fatty acids decreased. In MF, the proportion of lipids increased, while carbohydrates and peptides decreased. No changes were detected in the unfertilised treatment (CL). The discrimination of relative mass signals with PLSR to explain cumulated $\mathrm{CO}_{2}$ efflux revealed mainly functional groups from ketones and amides, peptides, carbohydrates, and lignin building blocks and fatty acids (Table 3 ).

Linear correlations were calculated to check relationships between HWC, HWN and soil respiration as indicators of SOM dynamics (Kuzyakov, 2006; Leinweber et al., 1995) and the absolute signal counts of the compound classes (Fig. 6). The latter was derived from Table 2 by Eq. (2).

$\mathrm{CII}_{\mathrm{abs}}=\frac{\mathrm{TII} \times \mathrm{CII}_{\mathrm{rel}}}{100}$,

with $\mathrm{CII}_{\mathrm{abs}}$ the absolute ion intensity of the respective compound class, TII the total ion intensity and $\mathrm{CII}_{\text {rel }}$ the proportion of the ion intensity of the respective compound class.

In MF, the ion intensities for carbohydrates were positively correlated with HWC $\left(R^{2}=0.44\right)$, whereas, in contrast, no such a correlation was found in BD. However, HWN showed a positive correlation with carbohydrates in $\mathrm{BD}\left(R^{2}=0.61\right)$. Further, $\mathrm{CO}_{2}$ efflux increased with decreasing amounts of sterols in BD $\left({ }^{2}=0.40\right)$.

\section{Discussion}

\subsection{Bulk soil and hot-water-extracted carbon and nitrogen}

The C, HWC, N and HWN contents of the treatments showed no differences before tillage (Table 1), thus confirming the outcomes of other field experiments with similar fertilisers (Makádi et al., 2016; Odlare et al., 2014). However, the C and $\mathrm{N}$ contents obtained may not be representative of longterm effects of biogas digestate vs. mineral fertiliser, which may also depend on soil texture (Makádi et al., 2016).

The increase in HWN in BD after tillage indicates an increase in easily mineralisable organic $\mathrm{N}$ which probably originates from soil biomass and lysates (Ghani et al., 2003; Leinweber et al., 1995) and implies an accelerated microbial turnover of soil organic $\mathrm{N}$. This seems reasonable since the microbial community is able to adjust its structure and activity relatively fast to utilise formerly protected organic matter after exposure due to disruption of aggregates by tillage (Jackson et al., 2003; La Scala et al., 2008). Accordingly, Fiedler et al. (2015) observed a short-lived increase in HWC after the first of 2 days of several tillage operations which was not found in the present study. It is possible that we did not detect it because we did not take any soil samples after the first day. Overall, a single amendment with biogas digestates is very likely insufficient to initiate changes in bulk soil $\mathrm{C}$ and $\mathrm{N}$ levels. However, the increased HWN levels in BD 
Table 3. Results of iterative partial least-squares regression for cumulated $\mathrm{CO}_{2}$ efflux as an dependent variable and $m / z$ data of all treatments and sampling times as explaining variables.

\begin{tabular}{ll}
\hline$m / z$ & Molecule/compound class \\
\hline $17 / 18$ & Ammonia/ammonium \\
31 & {$[M+H]^{+}$of formaldehyde } \\
34 & $\mathrm{H}_{2} \mathrm{~S}$ \\
43 & $\mathrm{C}_{2} \mathrm{H}_{3} \mathrm{O}$ from ketones/amides and $\mathrm{C}_{3} \mathrm{H}_{7}$ propyl \\
46 & $\mathrm{Formic}$ acid \\
55 & $\mathrm{C}_{3} \mathrm{H}_{3} \mathrm{O}$ from ketones/amides \\
57 & $\mathrm{C}_{3} \mathrm{H}_{5} \mathrm{O}$ from ketones/amides and $\mathrm{C}_{4} \mathrm{H}_{9}$ butyl \\
73 & Propanamide $_{83}$ \\
85 & $\mathrm{C}_{5} \mathrm{H}_{9} \mathrm{~N}$ from peptides \\
91 & $\mathrm{C}_{4} \mathrm{H}_{5} \mathrm{O}_{2}$ from carbohydrates \\
$98 / 99$ & Fragment from peptides \\
$206,222,230 / 231,246,254,258$ & Carbohydrates \\
$296,299,337,418,424$ & Lignins \\
\hline
\end{tabular}

can be ascribed to a tillage-promoted microbial turnover of soil organic $\mathrm{N}$, confirming that the hot-water extracts are a particularly sensitive approach to detect early SOM changes (Haynes, 2005).

\subsection{Soil $\mathrm{CO}_{2}$ efflux}

The immediate and sharp increase of $\mathrm{CO}_{2}$ efflux from soils just after tillage is a well-documented response and seems to be mainly driven by the release of trapped $\mathrm{CO}_{2}$ from aggregates broken up by tillage (Reicosky et al., 1997). It is commonly suggested that a decrease in this physical outgassing a few hours afterwards is accompanied by increased soil respiration due to a better substrate supply for microorganisms from disrupted aggregates as well as increased soil aeration (Grandy and Robertson, 2007). The amounts of the observed fluxes are well in accordance with the findings of previous studies (e.g. Rochette and Angers, 1999) and can be explained by both the magnitude of the disturbance, i.e. soil comminution, and the fertilisation history of the soil (Fiedler et al., 2015).

The smaller relative efflux from BD compared to MF and $\mathrm{CL}$ after tillage is remarkable since before tillage the $\mathrm{CO}_{2}$ fluxes in BD were of the same magnitude as those in MF and exceeded those in CL (Fig. 2). This becomes particularly evident when we consider the relation of cumulated $\mathrm{CO}_{2}$ fluxes between the treatments before ( 19 October) and after tillage (24-29 October) (Fig. 3). The relatively lower $\mathrm{CO}_{2}$ efflux from $\mathrm{BD}$ after tillage may have different reasons. On the one hand, $\mathrm{C}$ originating from the digestates is likely less available to soil microorganisms compared to undigested organic matter, i.e. more "recalcitrant", since the most labile $\mathrm{C}$ is generally consumed in the biogas reactor (Möller, 2015). On the other hand, even a single application of organic amendment can increase aggregate stability (Grandy et al., 2002). There- fore, the resilience against disruption by tillage might be promoted, leading to a better physical protection of labile soil $\mathrm{C}$ not contained within digestates. As a consequence, the effect of increased $\mathrm{CO}_{2}$ efflux after tillage as observed in CL and MF may have been substantially reduced by a relative shortage of labile substrate for soil respiration in BD.

\subsection{Pyrolysis-field ionisation mass spectrometry and synthesis}

Generally, the Py-FIMS basic data and mass spectra (Fig. 4) and the proportions of compound classes (Table 2) confirm published data from this method for Luvisols in terms of relatively high proportions of lignin monomers, phenols and alkyl aromatics (Leinweber et al., 2009). Lignin monomers and phenols might be collectively attributed to residues of the just-harvested maize. Indeed, Gregorich et al. (1996) found that these are important components of maize leaves and roots as well as of the light fraction of the soil under this crop. Overall, the Py-FIMS data indicate differences in SOM composition between the fertilisation treatments as well as a pronounced impact of tillage in the MF and BD treatments (Fig. 5).

In the spectra of samples from $\mathrm{BD}$, the additional peak at $390^{\circ} \mathrm{C}$ in the $\mathrm{TII}$ thermogram (Fig. 4) can be attributed to mainly phenols and lignin monomers which likely originated from primary organic matter residues since this relatively low volatilisation temperature indicates labile and fairly undecomposed organic matter (Sleutel et al., 2011). It is reasonable to refer this organic matter to residues from the application of digestate. VM and TII, which are indicators of SOM content (Sorge et al., 1993), were larger in BD than in MF and CL before tillage (Table 2). This suggests a tendency to increased SOM content through application of digestate. The compound classes of $\mathrm{BD}$ revealed the 
largest proportions of lignin dimers, lipids, sterols, suberin and free fatty acids at the expense of carbohydrates, heterocyclic $\mathrm{N}$-containing compounds and peptides before tillage (Table 2). Such an SOM composition most likely reflects the cattle manure and plant residues of the biogas feedstock and their relative depletions (amides and polysaccharides) or enrichments (lignins and long-chain aliphatic compounds) during anaerobic fermentation (Möller, 2015; van Bochove et al., 1996). The pronounced tillage effect in this treatment which is obvious from the increased relative signal intensities of carbohydrates, phenols and lignin monomers, alkyl aromatics, heterocyclic N-containing compounds and peptides at the expense of lignin dimers, lipids, sterols and free fatty acids following tillage (Table 2) - suggests the decomposition of lignin and the new formation of carbohydrates and peptides. This is in line with reports of lignin decomposition being faster than that of the total SOM (Leinweber et al., 2008; Thevenot et al., 2010). Kalbitz et al. (2003) suggested that lignin-derived moieties and lipids are utilised by microorganisms at low initial availability of carbohydrates, accompanied by an accumulation of the resulting microbial metabolites like carbohydrates and peptides. Recently, Rinkes et al. (2016) also found that decomposers may break down lignin to acquire $\mathrm{C}$ for their metabolism in the $\mathrm{ab}$ sence of available labile $\mathrm{C}$. This suggestion is supported on the one hand by the effect of specific lignins on soil $\mathrm{CO}_{2}$ efflux (Table 3) since $\mathrm{CO}_{2}$ is an indicator for microbial decomposition activity (Kuzyakov, 2006). On the other hand, a relative increase in the signals for $m / z 125,167$, 185 and 203 was observed in the BD treatment (data not shown), which are assigned to the bacterial cell wall products $\mathrm{N}$-acetylmuramic acid and $\mathrm{N}$-acetylmuramyl-l-alanyl$d$-isoglutamine (Bahr and Schulten, 1983). Furthermore, the build-up of heterocyclic $\mathrm{N}$-containing compounds might also imply a relative shortage of available carbohydrates since reduced $\mathrm{C}$ availability during the microbial transformation of $\mathrm{N}$ is suggested to promote formation of heterocyclic $\mathrm{N}$ instead of $\mathrm{N}$ immobilisation (Follett and Schimel, 1989; Gillespie et al., 2014; Schulten and Hempfling, 1992). The increased proportion of lipids at the expense of carbohydrates and peptides in MF likely results from increased heterotrophic respiration of labile substrates driven by enhanced microbial activity after tillage (La Scala et al., 2008; Zakharova et al., 2014). Decreasing proportions of carbohydrates and decreasing relative signal intensities of $m / z 17$ and 18 (data not shown), which are assigned to ammonia and ammonium, also point to a microbial immobilisation in MF (Mengel, 1996). Accordingly, these two $\mathrm{m} / \mathrm{z}$ were also selected by the PLSR as explanatory signals for $\mathrm{CO}_{2}$ efflux (Table 3). The minor changes in SOM compounds in CL might be a consequence of the wider $\mathrm{HWC} / \mathrm{HWN}$ ratio compared to $\mathrm{MF}$ and $\mathrm{BD}$ since it indicates a lower availability of labile $\mathrm{N}$ for microbial utilisation (Mengel, 1996). However, the total $\mathrm{C} / \mathrm{N}$ ratios were not critical for microbial activity (Table 1) (Kuzyakov et al., 2000).
A significant $(p<0.05)$ and positive correlation was observed between HWC and carbohydrates in MF. This linkage was previously described by Leinweber et al. (1995) and attributed to microbial biomass (Ghani et al., 2003) and labile soil C (Sparling et al., 1998). In contrast, this correlation was not apparent in BD. This corroborates the assumption that microorganisms in BD may have been short of available labile C. Interestingly, HWN correlated positively with carbohydrates in BD. Since the major part of carbohydrates in soils originates from microorganisms and their residues (Gunina and Kuzyakov, 2015), this may suggest a metabolic coupling between carbohydrates and HWN because many N-cycling processes are mediated microbially (Isobe and Ohte, 2014).

Increased amounts of sterols are typically found in biogas digestates (Leinweber, 2016, unpublished Py-FIMS data). In $\mathrm{BD}$, the cumulated $\mathrm{CO}_{2}$ efflux and the amount of sterols was negatively correlated. This supports the suggestion of Heumann et al. $(2011,2013)$ that sterols may have an inhibitory effect on microorganisms of the $\mathrm{N}$ cycle and thus may slow down soil respiration. However, since the amounts of sterols decreased significantly after tillage in BD (Table 3), the actual sterol contribution to reduced $\mathrm{CO}_{2}$ efflux in $\mathrm{BD}$ relative to the other treatments cannot be ascertained by the present data set.

Our data and analyses suggest a short-term induction of enhanced microbial N-turnover by tillage in soils amended with biogas digestates, possibly co-occurring with the decomposition of lignin as a $\mathrm{C}$ source due to a relative shortage of carbohydrates. This is supported by the results of each of the methods used, i.e. (i) HWN as an indicator for labile $\mathrm{N}$ increased; (ii) lignins, ammonia and ammonium discriminated as explanatory variables for cumulated $\mathrm{CO}_{2}$ efflux by PLSR; and (iii) Py-FIMS data point at an increase in $\mathrm{N}$-containing compounds along with decomposition of lignins and formation of carbohydrates and peptides.

In MF, the depletion of HWC was linked to decreasing amounts of carbohydrates, certainly due to increased microbial respiration, though no significant correlation with $\mathrm{CO}_{2}$ efflux was found. No modifications were detected in CL, where the absence of amendment may have led to a relative shortage of labile $\mathrm{N}$ as indicated by the higher HWC / HWN ratio, which possibly prevented an enhanced microbial activity.

\subsection{Limitations}

Although the relatively small sampling areas around the bases in each treatment plot might suggest a "pseudoreplication" in soil sampling, we have evidence suggesting very high spatial variability in the soil, which alleviates this problem: in a master's thesis on spatial variability, Jacobs (2014) revealed that $\mathrm{N}_{2} \mathrm{O}$ fluxes from the soil of the study site show very high small-scale variability well below the metre scale. Therefore, we assume "real" (i.e. independent) replicates, though the comparison between the treat- 
ments should be done carefully because of possibly rather small differences. Thus, due to the potentially lowered influence of spatial variability, our sampling design might have biased our results towards the detection of even small temporal changes within the treatments. Because we are mainly interested in the impact of tillage, this limitation does not interfere with our findings.

\section{Conclusions}

Combining Py-FIMS, as a sensitive technique to detect differences and alterations of specific compound classes of SOM, with classical methods like hot-water extraction and measurements of soil $\mathrm{CO}_{2}$ efflux allowed us to gain a better understanding of short-term SOM turnover after tillage operations. After tillage, SOM composition of the investigated soil changed in the temporal scale of days and the changes varied significantly under different types of amendment. Particularly obvious were the turnover of lignin-derived substances and the depletion of carbohydrates due to soil respiration. Thus, in $\mathrm{BD}$, the SOM turnover was relatively fast, questioning the suggested recalcitrance of biogas digestates as stable leftovers of the anaerobic fermentation. Since we found indications of inhibitory effects of sterols on the $\mathrm{CO}_{2}$ efflux, which were previously reported in three independent studies on parameters of the $\mathrm{N}$ cycle, their long-term impact on SOM stocks should be examined more closely. Therefore, future investigations should address the short- and long-term turnover of SOM following various amendments, especially with the relatively new biogas digestates.

\section{Data availability}

The underlying research data can be accessed publicly via the Supplement.

\section{The Supplement related to this article is available online at doi:10.5194/soil-2-475-2016-supplement.}

Acknowledgements. We thank the technicians Steffen Kaufmane and Sascha Tittmar for their assistance during field work and the research facility for agriculture and fisheries of the federal state of Mecklenburg-Western Pomerania (LFA) in Gülzow for their co-operation, especially Jana Peters and Andreas Gurgel. We also thank Karsten Kalbitz, Steven Sleutel and an anonymous referee for their constructive criticism and suggestions regarding the manuscript. The joint research project underlying this report was funded by the German Federal Ministry of Food and Agriculture (funding identifier 22007910). Py-FIMS analyses in the Mass Spectrometry Laboratory of Soil Science were funded by the "Exzellenzförderprogramm" of the Ministry of Education, Science and Culture, federal state of Mecklenburg-Western Pomerania (project UR 07 079) as well as by the German Federal Ministry of Food and Agriculture (funding identifier 22400112).
Edited by: K. Kalbitz

Reviewed by: S. Sleutel and one anonymous referee

\section{References}

Bahr, U. and Schulten, H.-R.: Pyrolysis field ionization mass spectrometry of cell wall components and bacterial cell walls, J. Anal. Appl. Pyrol., 5, 27-37, doi:10.1016/0165-2370(83)800114, 1983.

Balesdent, J., Mariotti, A., and Boisgontier, D.: Effect of tillage on soil organic carbon mineralization estimated from ${ }^{13} \mathrm{C}$ abundance in maize fields, J. Soil Sci., 41, 587-596, doi:10.1111/j.1365-2389.1990.tb00228.x, 1990.

Balota, E. L., Colozzi-Filho, A., Andrade, D. S., and Dick, R. P.: Microbial biomass in soils under different tillage and crop rotation systems, Biol. and Fertility of Soils, 38, 15-20, doi:10.1007/s00374-003-0590-9, 2003.

Barker, M. and Rayens, W.: Partial least squares for discrimination, J. Chemometr., 17, 166-173, doi:10.1002/cem.785, 2003.

Bauwe, A., Jurasinski, G., Scharnweber, T., Schröder, C., and Lennartz, B.: Impact of climate change on tree-ring growth of Scots pine, common beech and pedunculate oak in northeastern Germany, iForest, 9, 1-11, doi:10.3832/ifor1421-008, 2015.

Dao, T. H.: Tillage and crop residue effects on carbon dioxide evolution and carbon storage in a Paleustoll, Soil Sci. Soc. Am. J., 62, 250-256, 1998.

Doran, J. W.: Soil Microbial and Biochemical Changes Associated with Reduced Tillage, Soil Sci. Soc. Am. J., 44, 765-771, doi:10.2136/sssaj1980.03615995004400040022x, 1980.

Fiedler, S. R., Buczko, U., Jurasinski, G., and Glatzel, S.: Soil respiration after tillage under different fertiliser treatments - implications for modelling and balancing, Soil Till. Res., 150, 30-42, doi:10.1016/j.still.2014.12.015, 2015.

Follett, R. F. and Schimel, D. S.: Effect of Tillage Practices on Microbial Biomass Dynamics, Soil Sci. Soc. Am. J., 53, 10911096, doi:10.2136/sssaj1989.03615995005300040018x, 1989.

Franzluebbers, A. J., Hons, F. M., and Zuberer, D. A.: Seasonal changes in soil microbial biomass and mineralizable $\mathrm{C}$ and $\mathrm{N}$ in wheat management systems, Soil Biol. Biochem., 26, 14691475, doi:10.1016/0038-0717(94)90086-8, 1994.

Ghani, A., Dexter, M., and Perrott, K. W.: Hot-water extractable carbon in soils: a sensitive measurement for determining impacts of fertilisation, grazing and cultivation, Soil Biol. Biochem., 35, 1231-1243, doi:10.1016/S0038-0717(03)00186-X, 2003.

Gillespie, A. W., Diochon, A., Ma, B. L., Morrison, M. J., Kellman, L., Walley, F. L., Regier, T. Z., Chevrier, D., Dynes, J. J., and Gregorich, E. G.: Nitrogen input quality changes the biochemical composition of soil organic matter stabilized in the fine fraction: a long-term study, Biogeochemistry, 117, 337-350, doi:10.1007/s10533-013-9871-z, 2014.

Grandy, A. S. and Robertson, G.: Land-Use Intensity Effects on Soil Organic Carbon Accumulation Rates and Mechanisms, Ecosystems, 10, 59-74, doi:10.1007/s10021-006-9010-y, 2007.

Grandy, A. S., Porter, G. A., and Erich, M. S.: Organic Amendment and Rotation Crop Effects on the Recovery of Soil Organic Matter and Aggregation in Potato Cropping Systems, Soil Sci. Soc. America J., 66, 1311-1319, doi:10.2136/sssaj2002.1311, 2002. 
Grandy, A. S. and Neff, J. C.: Molecular C dynamics downstream: The biochemical decomposition sequence and its impact on soil organic matter structure and function, Sci. Total Environ., 404, 297-307, doi:10.1016/j.scitotenv.2007.11.013, 2008.

Gregorich, E. G., Monreal, C. M., Schnitzer, M., and Schulten, H. R.: Transformation of plant residues into soil organic matter: Chemical characterization of plant tissue, isolated soil fractions, and whole soils, Soil Science, 161, 680-693, doi:10.1097/00010694-199610000-00005, 1996.

Gunina, A. and Kuzyakov, Y.: Sugars in soil and sweets for microorganisms: Review of origin, content, composition and fate, Soil Biol. Biochem., 90, 87-100, doi:10.1016/j.soilbio.2015.07.021, 2015.

Haynes, R. J.: Labile Organic Matter Fractions as Central Components of the Quality of Agricultural Soils: An Overview, in: Advances in Agronomy, edited by: Sparks, D. L., Academic Press, San Diego, USA, 221-268, 2005.

Heumann, S., Schlichting, A., Boettcher, J., and Leinweber, P.: Sterols in soil organic matter in relation to nitrogen mineralization in sandy arable soils, J. Plant Nutr. Soil Sci., 174, 576-586, doi:10.1002/jpln.200900273, 2011.

Heumann, S., Rimmer, D. L., Schlichting, A., Abbott, G. D., Leinweber, P., and Böttcher, J.: Effects of potentially inhibiting substances on $\mathrm{C}$ and net $\mathrm{N}$ mineralization of a sandy soil - a case study, J. Plant Nutr. Soil Sci., 176, 35-39, doi:10.1002/jpln.201200353, 2013.

Isobe, K. and Ohte, N.: Ecological Perspectives on Microbes Involved in N-Cycling, Microb. Environ., 29, 4-16, doi:10.1264/jsme2.ME13159, 2014.

IUSS Working Group WRB: World Reference Base for Soil Resources 2006, World Soil Resources Report No. 103, FAO, Rome, 2006.

Jackson, L. E., Calderon, F. J., Steenwerth, K. L., Scow, K. M., and Rolston, D. E.: Responses of soil microbial processes and community structure to tillage events and implications for soil quality, Geoderma, 114, 305-317, doi:10.1016/S00167061(03)00046-6, 2003.

Jacobs, O.: Vergleich von zwei unterschiedlichen Kammersystemen zur Messung von bodenbürtigen Lachgasflüssen, MS thesis, University of Rostock, Rostock, 2014.

Jandl, G., Leinweber, P., Schulten, H.-R., and Eusterhues, K.: The concentrations of fatty acids in organo-mineral particlesize fractions of a Chernozem, Eur. J. Soil Sci., 55, 459-470, doi:10.1111/j.1365-2389.2004.00623.x, 2004.

Jurasinski, G., Koebsch, F., Guenther, A., Beetz, S.: Flux: Flux rate calculation from dynamic closed chamber measurements, $\mathrm{R}$ package version 0.3-0, http://CRAN.R-project.org/package= flux (last access: 6 September 2016), 2014.

Kalbitz, K., Schwesig, D., Schmerwitz, J., Kaiser, K., Haumaier, L., Glaser, B., Ellerbrock, R., and Leinweber, P.: Changes in properties of soil-derived dissolved organic matter induced by biodegradation, Soil Biol. Biochem., 35, 1129-1142, doi:10.1016/S00380717(03)00165-2, 2003.

Kuzyakov, Y.: Sources of $\mathrm{CO}_{2}$ efflux from soil and review of partitioning methods, Soil Biol. Biochem., 38, 425-448, doi:10.1016/j.soilbio.2005.08.020, 2006.

Kuzyakov, Y., Friedel, J. K., and Stahr, K.: Review of mechanisms and quantification of priming effects, Soil Biol. Biochem., 32, 1485-1498, doi:10.1016/S0038-0717(00)00084-5, 2000.
Kuzyakov, Y., Leinweber, P., Sapronov, D., and Eckhardt, K.U.: Qualitative assessment of rhizodeposits in non-sterile soil by analytical pyrolysis, J. Plant Nutr. Soil Sci., 166, 719-723, doi:10.1002/jpln.200320363, 2003.

La Scala, N., Lopes, A., Spokas, K., Bolonhezi, D., Archer, D. W., and Reicosky, D. C.: Short-term temporal changes of soil carbon losses after tillage described by a first-order decay model, Soil Till. Res., 99, 108-118, doi:10.1016/j.still.2008.01.006, 2008.

Leinweber, P., Schulten, H. R., and Korschens, M.: Hot-water extracted organic-matter-chemical-composition and temporal variations in a long-term field experiment, Biol. Fert. Soils, 20, 1723, doi:10.1007/BF00307836, 1995.

Leinweber, P., Jandl, G., Baum, C., Eckhardt, K.-U., and Kandeler, E.: Stability and composition of soil organic matter control respiration and soil enzyme activities, Soil Biol. Biochem., 40, 14961505, doi:10.1016/j.soilbio.2008.01.003, 2008.

Leinweber, P., Jandl, G., Eckhardt, K.-U., Schulten, H.-R., Schlichting, A., and Hofmann, D.: Analytical Pyrolysis and SoftIonization Mass Spectrometry, in: Biophysico-chemical processes involving natural nonliving organic matter in environmental systems, Wiley-IUPAC series in biophysico-chemical processes in environmental systems, edited by: Senesi, N., Xing, B., and Huang, P. M., Wiley, Hoboken, NJ, 2009.

Leinweber, P., Kruse, J., Baum, C., Arcand, M., Knight, J. D., Farrell, R., Eckhardt, K.-U., Kiersch, K., and Jandl, G.: Chapter Two - Advances in Understanding Organic Nitrogen Chemistry in Soils Using State-of-the-art Analytical Techniques, in: Advances in Agronomy, edited by: Sparks, D. L., Academic Press, San Diego, USA, 83-151, 2013.

Makádi, M., Szegi, T., Tomócsik, A., Orosz, V., Michéli, E., Ferenczy, A., Posta, K., and Biró, B.: Impact of Digestate Application on Chemical and Microbiological Properties of Two Different Textured Soils, Commun. Soil Sci. Plant Anal., 47, 167-178, doi:10.1080/00103624.2015.1109652, 2016.

Melnitchouck, A., Leinweber, P., Eckhardt, K. U., and Beese, R.: Qualitative differences between day- and night-time rhizodeposition in maize (Zea mays L.) as investigated by pyrolysis-field ionization mass spectrometry, Soil Biol. Biochem., 37, 155-162, doi:10.1016/j.soilbio.2004.06.017, 2005.

Mengel, K.: Turnover of organic nitrogen in soils and its availability to crops, Plant Soil, 181, 83-93, doi:10.1007/BF00011295, 1996.

Möller, K.: Effects of anaerobic digestion on soil carbon and nitrogen turnover, $\mathrm{N}$ emissions, and soil biological activity. A review, Agron. Sustain. Dev., 35, 1021-1041, doi:10.1007/s13593-0150284-3, 2015.

Odlare, M., Pell, M., Arthurson, J. V., Abubaker, J., and Nehrenheim, E.: Combined mineral $\mathrm{N}$ and organic waste fertilization effects on crop growth and soil properties, J. Agricult. Sci., 152, 134-145, doi:10.1017/S0021859612001050, 2014.

Oksanen, J., Guillaume Blanchet, F., Kindt, R., Legendre, P., Minchin, P. R., O’Hara, R. B., Simpson, G. L., Solymos, P., Stevens, M. H. H., and Wagner, H.: vegan: Community Ecology Package, R package version 2.3-0, http://CRAN.R-project. org/package=vegan (last access: 6 September 2016), 2015.

R Core Team: R: A language and environment for statistical computing, R Foundation for Statistical Computing, Vienna, Austria, http://www.R-project.org (last access: 6 September 2016), 2013.

Reicosky, D. C., Dugas, W. A., and Torbert, H. A.: Tillage-induced soil carbon dioxide loss from different cropping systems, Soil 
Till. Res., 41, 105-118, doi:10.1016/S0167-1987(96)01080-X, 1997.

Rinkes, Z. L., Bertrand, I., Amin, B. A. Z., Grandy, A. S., Wickings, K., and Weintraub, M. N.: Nitrogen alters microbial enzyme dynamics but not lignin chemistry during maize decomposition, Biogeochemistry, 128, 171-186, doi:10.1007/s10533-016-02010, 2016.

Rochette, P. and Angers, D. A.: Soil surface carbon dioxide fluxes induced by spring, summer, and fall moldboard plowing in a sandy loam, Soil Sci. Soc. Am. J., 63, 621-628, 1999.

Schmidt, L., Warnstorff, K., Dörfel, H., Leinweber, P., Lange, H., and Merbach, W.: The influence of fertilization and rotation on soil organic matter and plant yields in the long-term Eternal Rye trial in Halle (Saale), Germany, J. Plant Nutr. Soil Sci., 163, 639648, 2000.

Schmidtlein, S., Feilhauer, H., and Bruelheide, H.: Mapping plant strategy types using remote sensing, J. Veg. Sci., 23, 365-405, doi:10.1111/j.1654-1103.2011.01370.x, 2012.

Schulten, H.-R. and Hempfling, R.: Influence of agricultural soil management on humus composition and dynamics: Classical and modern analytical techniques, Plant Soil, 142, 259-271, doi:10.1007/BF00010971, 1992.

Schulten, H. R., Leinweber, P., and Jandl, G.: Analytical pyrolysis of humic substances and dissolved organic matter in water, in: Refractory organic substances in the environment, edited by: Frimmel, F. H., Abbt-Braun, G., Heumann, K. G., Hock, B., Lüdemann, H.-D., and Spiteller, M., John Wiley \& Sons, Weinheim, Germany, 163-187, 2008.
Sleutel, S., Leinweber, P., van Ranst, E., Kader, M. A., and Jegajeevagan, K.: Organic Matter in Clay Density Fractions from Sandy Cropland Soils with Differing Land-Use History, Soil Sci. Soc. Am. J., 75, 521-532, doi:10.2136/sssaj2010.0094, 2011.

Sorge, C., Müller, R., Leinweber, P., and Schulten, H.-R.: Pyrolysismass spectrometry of whole soils, soil particle-size fractions, litter materials and humic substances: statistical evaluation of sample weight, residue, volatilized matter and total ion intensity, Fresen. J. Anal. Chem., 346, 697-703, doi:10.1007/BF00321275, 1993.

Sparling, G., Vojvodic-Vukovic, M., and Schipper, L. A.: Hotwater-soluble $\mathrm{C}$ as a simple measure of labile soil organic matter: the relationship with microbial biomass C, Soil Biol. Biochem., 30, 1469-1472, doi:10.1016/S0038-0717(98)00040-6, 1998.

Thevenot, M., Dignac, M.-F., and Rumpel, C.: Fate of lignins in soils: A review, Soil Biol. Biochem., 42, 1200-1211, doi:10.1016/j.soilbio.2010.03.017, 2010.

van Bochove, E., Couillard, D., Schnitzer, M., and Schulten, H.-R.: Pyrolysis-Field Ionization Mass Spectrometry of the Four Phases of Cow Manure Composting, Soil Sci. Soc. Am. J., 60, 17811786, doi:10.2136/sssaj1996.03615995006000060024x, 1996.

Zakharova, A., Midwood, A. J., Hunt, J. E., Graham, S. L., Artz, R. R. E., Turnbull, M. H., Whitehead, D., and Millard, P.: Loss of labile carbon following soil disturbance determined by measurement of respired $\delta^{13} \mathrm{CO}_{2}$, Soil Biol. Biochem., 68, 125-132, doi:10.1016/j.soilbio.2013.10.001, 2014. 